\title{
BMJ Open Disability pension due to common mental disorders and subsequent suicidal behaviour: a population-based prospective cohort study
}

\author{
Syed Ghulam Rahman, ${ }^{1}$ Kristina Alexanderson, ${ }^{1}$ Jussi Jokinen, ${ }^{2,3}$ \\ Ellenor Mittendorfer-Rutz ${ }^{1}$
}

To cite: Rahman SG, Alexanderson K, Jokinen J, et al. Disability pension due to common mental disorders and subsequent suicidal behaviour: a populationbased prospective cohort study. BMJ Open 2016;6: e010152. doi:10.1136/ bmjopen-2015-010152

- Prepublication history for this paper is available online. To view these files please visit the journal online (http://dx.doi.org/10.1136/ bmjopen-2015-010152).

Received 1 October 2015 Revised 11 March 2016 Accepted 17 March 2016

CrossMark

\begin{abstract}
${ }^{1}$ Division of Insurance Medicine, Department of Clinical Neuroscience, Karolinska Institutet, Stockholm, Sweden ${ }^{2}$ Division of Psychiatry, Department of Clinical Neuroscience, Karolinska Institutet, Karolinska University Hospital, Stockholm, Sweden ${ }^{3}$ Division of Psychiatry, Department of Clinical Sciences, Umeå University, Umeå, Sweden
\end{abstract}

Correspondence to Dr Syed Ghulam Rahman; syed.rahman@ki.se

\section{ABSTRACT \\ Objective: Adverse health outcomes, including} suicide, in individuals on disability pension (DP) due to mental diagnoses have been reported. However, scientific knowledge on possible risk factors for suicidal behaviour (suicide attempt and suicide) in this group, such as age, gender, underlying DP diagnoses, comorbidity and DP duration and grade, is surprisingly sparse. This study aimed to investigate associations of different measures (main and secondary diagnoses, duration and grade) of DP due to common mental disorders (CMD) with subsequent suicidal behaviour, considering gender and age differences.

Design: Population-based prospective cohort study based on Swedish nationwide registers.

Methods: A cohort of 46515 individuals aged 19-64 years on DP due to CMD throughout 2005 was followed-up for 5 years. In relation to different measures of DP, univariate and multivariate $\mathrm{HRs}$ and $95 \% \mathrm{Cls}$ for suicidal behaviour were estimated by Cox regression. All analyses were stratified by gender and age.

Results: During 2006-2010, 1036 (2.2\%) individuals attempted and 207 (0.5\%) completed suicide. Multivariate analyses showed that a main DP diagnosis of 'stressrelated mental disorders' was associated with a lower risk of subsequent suicidal behaviour than 'depressive disorders' (HR range 0.4-0.7). Substance abuse or personality disorders as a secondary DP diagnosis predicted suicide attempt in all subgroups (HR range 1.4-2.3) and suicide in women and younger individuals (HR range 2.6-3.3). Full-time DP was associated with a higher risk of suicide attempt compared with part-time DP in women and both age groups (HR range 1.4-1.7).

Conclusions: Depressive disorders as the main DP diagnosis and substance abuse or personality disorders as the secondary DP diagnosis were risk markers for subsequent suicidal behaviour in individuals on DP due to CMD. Particular attention should be paid to younger individuals on DP due to anxiety disorders because of the higher suicide risk.

\section{BACKGROUND}

Disability pension (DP) is a major public health issue in many European countries ${ }^{12}$

\section{Strengths and limitations of this study}

- This population-based, prospective cohort study used data of high quality.

- The study did not suffer from any loss to follow-up.

- Considered diagnoses were not self-reported, but derived from administrative registers and provided by physicians.

- Some analyses were based on only a few suicide cases.

- We considered suicide attempts that led to inpatient care, thus the results are mainly valid for suicide attempts of greater medical severity.

and increasingly so regarding mental DP diagnoses. $^{1}{ }^{3-5}$ In Sweden in 2012, mental diagnoses accounted for $40 \%$ of the DPs granted to individuals aged $30-64$ years and for $84 \%$ among those aged $19-29$ years. ${ }^{3}$ The majority of the mental DP diagnoses are common mental disorders (CMD) - that is, depressive, anxiety or stress-related mental disorders. ${ }^{16}$ These are diagnoses for which treatment and rehabilitation measures are available, and inactivity-for example, in terms of long-term or permanent exclusion from work due to DP-may have adverse effects. ${ }^{7}$ DP itself may imply alteration of health behaviour (eg, regarding alcohol and tobacco use, exercise, diet) or social isolation. ${ }^{8}$ This can be due to lack of ties to the labour market and eventually lack of the potential positive effects of paid work, including social contacts with colleagues, prospects of career and income progression, a sense of purpose, or even daily routines and structures. ${ }^{9}$ It is possible that individuals who have been on DP for a shorter period might experience fewer adverse effects of being excluded from the labour market than individuals on DP for a longer time. ${ }^{10}$ Similarly, 
part-time DP might be more protective concerning such adverse health or social outcomes than full-time DP. ${ }^{11} 12$

Adverse health outcomes, including suicide, among 'disability pensioners', especially those granted a DP early in adult life because of mental diagnoses, have been shown previously. ${ }^{8} 13$ However, to date little is known about specific risk factors related to eventual worse outcomes in individuals on $\mathrm{DP}^{8}$ such as suicide attempt or suicide. Suicidal behaviour can be considered the most extreme consequence of mental disorders, particularly depressive disorders or depression comorbid with anxiety. ${ }^{14-16}$ Patients with a depressive disorder have a higher risk of subsequent suicidal behaviour in the case of comorbidity with another mental or a somatic disorder, than patients with depressive disorders without such comorbidity. ${ }^{17-19}$ To date, knowledge is lacking regarding associations between DP due to different diagnoses with and without comorbidity with regard to subsequent suicidal behaviour.

There are well-documented gender and age differences with regard to both DP and suicidal behaviour. ${ }^{13} 1420$ However, there is a lack of studies investigating if gender and age are associated with suicidal behaviour among recipients of DP due to CMD, and across different measures of DP (such as main diagnosis, secondary diagnosis, duration and grade). Previous studies have found that sociodemographic factors, such as educational level, family situation, country of birth, and type of area of residence, are associated with morbidity (defined as previous suicide attempt or in- or out-patient care due to mental diagnoses) and subsequent suicidal behaviour. ${ }^{14} 17$ 21-24 In addition, excess mortality including suicide among DP recipients due to mental diagnoses compared with the general population not on DP has been reported..$^{25-27}$ Therefore, it is relevant to take account of sociodemographic factors and health factors in analyses of the association between DP and subsequent suicidal behaviour.

\section{Aim}

This study aimed to examine (1) how different measures of DP (main diagnosis, secondary diagnosis, duration and grade) were associated with subsequent suicidal behaviour (suicide attempt and suicide) in individuals on DP due to CMD and (2) possible differences in these associations with regard to gender and age.

\section{METHODS AND MATERIALS Design}

A nationwide population-based prospective cohort study based on Swedish register data was conducted. The cohort comprised all individuals aged 19-64 years, living in Sweden on 31 December 2004, who were on full- or part-time DP due to CMD throughout 2005 ( $n=48$ 803). Individuals treated as inpatients or with specialised outpatient healthcare on the schizophrenic spectrum or with bipolar disorders or having this as a secondary DP diagnosis in 2001-2005 ( $\mathrm{n}=1886)$ and people receiving old-age pension during $2005(\mathrm{n}=402)$ were excluded. The final cohort therefore included 46515 individuals. They were followed-up for 5 years (2006-2010).

Annual data covering 2001-2010 were obtained from the following four nationwide registers: (1) longitudinal integration database for health insurance and labour market studies (LISA) held by Statistics Sweden, including sociodemographic information on gender, age, educational level, type of area of residence, country of birth, family situation; (2) two registers held by the National Board of Health and Welfare, namely (i) National Patient Register including information on date and diagnosis of inpatient and specialised outpatient care and (ii) Cause of Death Register with data on date and cause of death; (3) micro-data for analyses of social insurance (MiDAS) with information on the date, diagnoses (the main and secondary DP diagnoses), duration and grade of DP from the National Social Insurance Agency. Data from these registers were linked at individual level using the unique personal identification number of all residents in Sweden.

\section{The DP system in Sweden}

All residents in Sweden aged 19-64 years who, because of disease or injury, have a long-lasting or permanent reduction in their work capacity can be granted a temporary or permanent DP from the Social Insurance Agency for $25 \%, 50 \%, 75 \%$, or $100 \%$ of ordinary working hours. ${ }^{3}$ Since 2003, individuals aged 19-29 years can also be granted a temporary DP if health reasons lead to failure to complete compulsory or upper secondary school in due time. ${ }^{3}$ DP amounts to $65 \%$ of lost income, up to a certain level. For those with no previous income, there is a minimum sum.

\section{Risk factors}

\section{Main and secondary DP diagnoses}

All information on DP diagnoses was based on the corresponding codes of the International Classification of Diseases, V.10 (ICD-10). ${ }^{28}$ Information on the main and secondary DP diagnoses was available from MiDAS.

Main DP diagnoses were categorised as: 'depressive disorders' including 'depressive episode' (F32) and 'recurrent depressive disorder' (F33); 'anxiety disorders' comprising 'phobic anxiety disorder' (F40); 'other anxiety disorder' (F41); 'obsessive-compulsive disorder' (F42); and 'stressrelated mental disorders' including 'reaction to severe stress, adjustment disorders, acute stress reaction and posttraumatic stress disorder' (F43). ${ }^{29} 30$

Secondary diagnoses were categorised as: 'no secondary diagnosis'; 'substance abuse disorders' (F10-F19); 'personality disorders' (F60-F69); 'other mental disorders' (F00-F99 except F10-F19, F60-F69); 'musculoskeletal disorders' (M00-M99); and 'other somatic disorders' (all diagnoses except M00-M99 and F00-F99).

The excluded bipolar and schizophrenic spectrum disorders included the following ICD-10 codes: F20-F29 and F31. 


\section{Duration}

DP duration was calculated by subtracting the start date of DP from the end date of exposure (31 December 2005) in gross days. Thereafter, the days were converted into years and were categorised as ' 1 year', '2-3 years' or ' $\geq 4$ years'.

\section{Grade}

Grade of DP, in 2005, was categorised as full-time (100\%) or part-time $(25 \%, 50 \%$ or $75 \%)$.

\section{Confounders}

All sociodemographic characteristics were measured at baseline (31 December 2004): age, gender, educational level, family situation, country of birth, and type of area of residence. Age was dichotomised into 19-44 and 45-64 years. Educational level was categorised into three groups according to the total number of years of education at three levels: 'compulsory (0-9 years)', 'upper secondary (10-12 years)', and 'university ( $\geq 13$ years)'. Family situation was coded into four groups: 'married/ cohabiting with children living at home', 'married/cohabiting with no children living at home', 'single without children living at home', and 'single with children living at home'. Country of birth included 'Sweden', 'other Nordic countries', 'EU 25 (except Nordic countries)', and 'rest of the world'. Type of area of residence was divided into 'big cities', 'medium-sized cities' and 'small cities/villages'. Missing values were coded as separate categories. Healthcare factors-that is, previous suicide attempt, inpatient and specialised outpatient care due to mental diagnoses-were measured from 2001 to 2005 and were dichotomised as 'yes' and 'no'.

\section{Outcome measures}

The outcome was suicidal behaviour in terms of suicide attempt or completed suicide.

Information on suicide attempt and suicide in 20062010 was obtained from the inpatient-care and cause of death register, respectively. As suicides are often underreported or reported as 'undetermined' causes, ${ }^{31} 32$ information on 'determined' (X60-84) and 'undetermined' (Y10-34) suicide was combined to limit underreporting and to compensate for regional and temporal variation in ascertainment methods. A similar procedure was performed for suicide attempt. This is a common procedure in research on suicidal behaviour. ${ }^{33}$ The combined outcome measures are hereafter called suicide attempt and suicide, respectively.

\section{Statistical analysis}

$\chi^{2}$ statistics were used to test significant gender and age differences in the cohort. Univariate HRs and 95\% CIs for the risk factors with regard to suicide attempt and suicide were estimated by Cox proportional hazard regression models, after confirming that the proportionate hazard assumption had been met. All individuals were followed-up from 1 January 2006 until the event (suicide attempt; suicide), emigration, death (due to causes other than X06-84 and Y10-34, in the analyses related to suicide as an outcome), or end of follow-up (31 December 2010), whichever occurred first. The partial likelihood ratio test was used to test for possible interactions between the exposure variables (main and secondary DP diagnoses, and duration and grade of DP) and age and gender in relation to the outcome measures. Multivariate models were built with adjustment for sociodemographic and healthcare factors and mutual adjustment for all other covariates. Before the outcome measures were combined, sensitivity analyses were carried out by calculating HRs and 95\% CIs for all exposure measures in relation to determined and undetermined suicide both separately and after combination. After ensuring that these estimates were comparable, we introduced the combined variable into the model. Similar tests were performed for determined and undetermined suicide attempt. All analyses were stratified by gender and age and performed using SPSS V.22.

\section{Ethics statement}

The project was evaluated and approved by the Regional Ethics Review Board of Stockholm, Sweden.

\section{RESULTS}

Of the 46515 individuals on DP due to CMD during 2005 , the majority $(66.4 \%)$ were women and $70 \%$ were aged 45-64 years (table 1). Nearly half of the women (48.3\%) had depressive disorders as the main DP diagnosis, while a large proportion of the men had anxiety disorders as the main DP diagnosis $(31.7 \%)$. Depressive disorders as the main DP diagnosis was more common among the older individuals (51.5\%), whereas anxiety disorders as the main DP diagnosis was more common among the younger ones $(43.1 \%)$. The two predominant main DP diagnoses for the entire cohort were 'depressive episode' $(36.8 \%)$ and 'stress-related mental disorder' $(23.6 \%)$ (data not shown in table 1 ).

In the cohort, nearly half of the individuals did not have any secondary DP diagnosis (43.1\%) (table 1). Substance abuse disorders as the secondary diagnosis was more prevalent among men and older individuals, while personality disorders were more common among women and younger individuals $(\mathrm{p}<0.001)$. The majority of the individuals had a full-time DP (75.6\%). A parttime DP was more common among women $(28 \%)$ than men $(17.4 \%)$ and among older $(26.7 \%)$ than younger $(19.2 \%)$ individuals $(\mathrm{p}<0.001)$.

Regarding the covariates, nearly half $(47 \%)$ of the study population had received upper secondary education, most lived in big or medium-sized cities $(74 \%)$, and $75 \%$ were born in Sweden (data not shown in table 1). Almost half (42\%) lived without a partner and without children at home.

In the cohort, $1036(2.2 \%)$ individuals were treated as inpatients due to a suicide attempt, and $207(0.5 \%)$ 


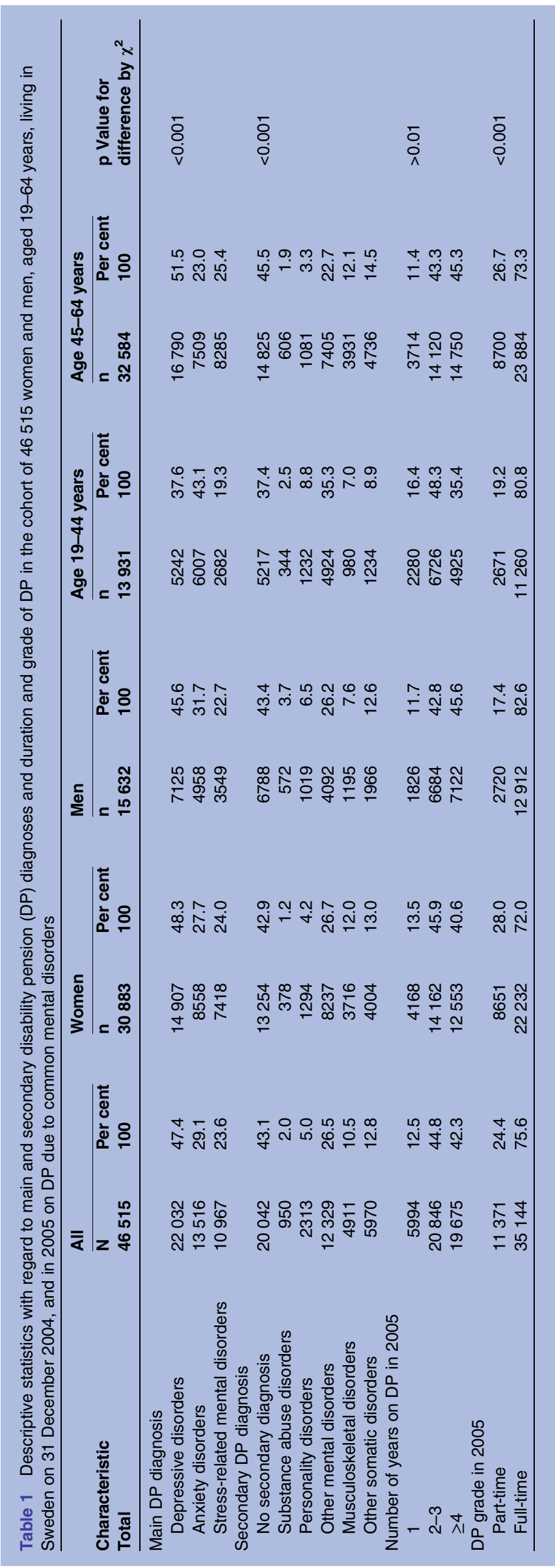

committed suicide during the 5-year follow-up (20062010) (table 2). Women were more likely than men to attempt suicide (women, 2.4\%; men, 2.0\%; p<0.01), while a higher proportion of men completed suicide (women, $0.3 \%$; men, $0.7 \%$; $<<0.001$ ). Mean follow-up time for suicide attempt and suicide was 4.85 (SD 0.70) and 4.91 (SD 0.52) years, respectively.

Tables 2 and 3 show univariate HRs and tables 4 and 5 show multivariate HRs for suicide attempt and suicide, stratified by gender and age with regard to main and secondary DP diagnoses as well as duration and grade of DP.

In the univariate analyses, 'anxiety disorders' as the main diagnosis was associated with a higher risk of suicide attempt in both women and men (range of HRs 1.4-1.5) and suicide in the younger age group (HR 1.9; 95\% CI 1.1 to 3.3) compared with 'depressive disorders' as the main diagnosis. These associations became insignificant after sociodemographic variables had been controlled for in the multivariate models, except for suicide in individuals aged 19-44 years (HR 1.7; 95\% CI 1.0 to 3.0). Compared with 'depressive disorders', 'stress-related mental disorders' as the main diagnosis was associated with a lower risk of both suicide attempt and suicide (except for women and the age group 19-44 years) in both crude and multivariate adjusted models. There was a significant interaction between age and main diagnosis ( $\mathrm{p}=0.017)$ regarding suicide. Individuals aged 45-64 years with a main DP diagnosis of 'stress-related mental disorders' had a significantly lower risk of committing suicide during the follow-up compared with individuals with 'depressive disorders' as the main DP diagnosis (HR 0.3; $95 \%$ CI 0.2 to 0.6 ). This association was not observed in younger individuals.

In the univariate models, all analysed mental secondary diagnoses were associated with a higher risk of subsequent suicide attempt, regardless of gender and age (range of HRs 1.2-7.1). These associations remained significant (range of HRs 1.3-2.3) in the multivariate models, except the association of 'other mental disorders' as the secondary diagnosis with subsequent suicide attempt in men and the age group 45-64 years. 'Substance abuse disorders' and 'personality disorders' as the secondary diagnosis were also associated with a higher risk of suicide (range of HRs 1.9-9.6) in women and in both age groups in the crude analyses compared with their counterparts without a secondary diagnosis. However, in the adjusted model, only 'substance abuse disorders' predicted suicide among women and younger individuals (range of HRs 2.6-3.3). A statistically significant interaction was found between gender and secondary diagnosis $(\mathrm{p}=0.029)$ in relation to subsequent suicide. Women with 'substance abuse disorders' or 'personality disorders' as the secondary DP diagnosis were at a higher risk of subsequent suicide compared with women without a secondary diagnosis. Such associations were not observed among men.

A DP duration of 4 years or more predicted suicide attempt in women and older individuals (range of HRs 


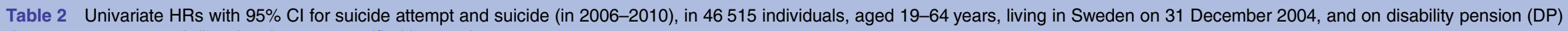
due to common mental disorders in 2005 , stratified by gender

\begin{tabular}{|c|c|c|c|c|c|c|c|c|c|c|c|c|}
\hline \multirow[b]{3}{*}{ Characteristic } & \multicolumn{6}{|c|}{ Suicide attempt } & \multicolumn{6}{|c|}{ Suicide } \\
\hline & \multicolumn{3}{|c|}{ Women } & \multicolumn{3}{|c|}{ Men } & \multicolumn{3}{|c|}{ Women } & \multicolumn{3}{|c|}{ Men } \\
\hline & $\bar{n}$ & Per cent & HR (95\% Cl) & $\mathrm{n}$ & Per cent & HR (95\% Cl) & $\mathrm{n}$ & Per cent & HR (95\% Cl) & $\mathrm{n}$ & Per cent & HR (95\% Cl) \\
\hline \multicolumn{13}{|l|}{ Main DP diagnosis } \\
\hline Depressive disorders & 355 & 34.3 & 1 & 139 & 13.4 & 1 & 53 & 25.6 & 1 & 50 & 24.2 & 1 \\
\hline Anxiety disorders & 278 & 26.8 & $1.4(1.2$ to 1.6$)$ & 140 & 13.5 & $1.5(1.1$ to 1.8$)$ & 32 & 15.5 & $1.1(0.7$ to 1.6$)$ & 47 & 22.7 & 1.3 (0.9 to 2.0$)$ \\
\hline Stress-related mental disorders & 99 & 9.6 & 0.6 (0.5 to 0.7$)$ & 25 & 2.4 & $0.4(0.2$ to 0.5$)$ & 17 & 8.2 & $0.6(0.4$ to 1.1$)$ & 8 & 3.9 & $0.3(0.2$ to 0.7$)$ \\
\hline \multicolumn{13}{|l|}{ Secondary DP diagnosis } \\
\hline No secondary diagnosis & 232 & 22.4 & 1 & 100 & 9.7 & 1 & 34 & 16.4 & 1 & 45 & 21.7 & 1 \\
\hline Substance abuse disorders & 43 & 4.2 & 7.1 (5.1 to 9.8$)$ & 34 & 3.3 & 4.3 (2.9 to 6.3$)$ & 9 & 4.3 & $9.6(4.6$ to 20.1$)$ & 7 & 3.4 & 1.9 (0.9 to 4.3$)$ \\
\hline Personality disorders & 83 & 8.0 & 3.8 (2.9 to 4.8$)$ & 39 & 3.8 & $2.7(1.8$ to 3.8$)$ & 12 & 5.8 & $3.6(1.9$ to 7.0$)$ & 9 & 4.4 & $1.3(0.7$ to 2.8$)$ \\
\hline Other mental disorders & 253 & 24.4 & $1.8(1.5$ to 2.1$)$ & 95 & 9.2 & $1.6(1.2$ to 2.1$)$ & 27 & 13.0 & $1.3(0.8$ to 2.1$)$ & 29 & 14.0 & $1.1(0.7$ to 1.7$)$ \\
\hline Musculoskeletal disorders & 56 & 5.4 & 0.9 (0.6 to 1.2$)$ & 10 & 1.0 & $0.6(0.3$ to 1.1$)$ & $<7$ & 2.9 & $0.6(0.3$ to 1.5$)$ & $<7$ & 2.4 & 0.6 (0.3 to 1.6$)$ \\
\hline Other somatic disorders & 65 & 6.3 & 0.9 (0.7 to 1.2$)$ & 26 & 2.5 & 0.9 (0.6 to 1.4$)$ & 14 & 6.8 & $1.4(0.7$ to 2.5$)$ & 10 & 4.8 & $0.8(0.4$ to 1.5$)$ \\
\hline \multicolumn{13}{|l|}{ Number of years on DP in 2005} \\
\hline 1 & 100 & 13.7 & 1 & 42 & 13.8 & 1 & 13 & 12.7 & 1 & 14 & 13.3 & 1 \\
\hline $2-3$ & 308 & 42.1 & $0.9(0.7$ to 1.1$)$ & 137 & 45.1 & $0.9(0.6$ to 1.3$)$ & 46 & 45.1 & $1.0(0.6$ to 1.9$)$ & 51 & 48.6 & $1.0(0.6$ to 1.8$)$ \\
\hline$\geq 4$ & 324 & 44.3 & $1.1(0.9$ to 1.4$)$ & 125 & 41.1 & $0.8(0.5$ to 1.1$)$ & 43 & 42.2 & $1.1(0.6$ to 2.1$)$ & 40 & 38.1 & 0.7 (0.4 to 1.4$)$ \\
\hline \multicolumn{13}{|l|}{ DP grade in 2005} \\
\hline Part-time & 84 & 8.1 & 1 & 42 & 4.1 & 1 & 16 & 7.7 & 1 & 10 & 4.8 & 1 \\
\hline Full-time & 648 & 62.8 & 3.1 (2.4 to 3.8$)$ & 262 & 25.4 & $1.3(1.0$ to 1.9$)$ & 86 & 41.6 & $2.1(1.2$ to 3.6$)$ & 95 & 45.9 & 2.0 (1.1 to 3.9$)$ \\
\hline
\end{tabular}

Table 3 Univariate HRs with 95\% Cl for suicide attempt and suicide (2006-2010), in 46515 individuals, aged 19-64 years and living in Sweden on 31 December 2004, and on disability pension (DP) due to common mental disorders in 2005 , stratified by age

\begin{tabular}{|c|c|c|c|c|c|c|c|c|c|c|c|c|}
\hline \multirow[b]{3}{*}{ Characteristic } & \multicolumn{6}{|c|}{ Suicide attempt } & \multicolumn{6}{|c|}{ Suicide } \\
\hline & \multicolumn{3}{|c|}{ Age $19-44$ years } & \multicolumn{3}{|c|}{ Age 45-64 years } & \multicolumn{3}{|c|}{ Age 19-44 years } & \multicolumn{3}{|c|}{ Age $45-64$ years } \\
\hline & $\mathrm{n}$ & Per cent & HR $(95 \% \mathrm{Cl})$ & $\bar{n}$ & Per cent & HR (95\% Cl) & $\mathrm{n}$ & Per cent & HR (95\% Cl) & $\mathrm{n}$ & Per cent & HR (95\% Cl) \\
\hline \multicolumn{13}{|l|}{ Main DP diagnosis } \\
\hline Depressive disorders & 217 & 21.0 & 1 & 277 & 26.7 & 1 & 20 & 9.7 & 1 & 83 & 43.0 & 1 \\
\hline Anxiety disorders & 278 & 26.8 & $1.1(0.9$ to 1.3$)$ & 140 & 13.5 & $1.1(0.9$ to 1.4$)$ & 44 & 21.3 & $1.9(1.1$ to 3.3$)$ & 35 & 16.9 & 0.9 (0.6 to 1.4$)$ \\
\hline Stress-related mental disorders & 62 & 6.0 & $0.6(0.4$ to 0.7$)$ & 62 & 6.0 & $0.5(0.3$ to 0.6$)$ & 12 & 5.8 & $1.2(0.6$ to 2.4$)$ & 13 & 6.3 & $0.3(0.2$ to 0.6$)$ \\
\hline \multicolumn{13}{|l|}{ Secondary DP diagnosis } \\
\hline No secondary diagnosis & 140 & 13.5 & 1 & 192 & 18.5 & 1 & 20 & 9.7 & 1 & 59 & 28.5 & 1 \\
\hline Substance abuse disorders & 40 & 3.9 & 4.7 (3.3 to 6.7$)$ & 37 & 3.6 & 5.0 (3.5 to 7.2 ) & 8 & 3.9 & $6.3(2.8$ to 14.3$)$ & 8 & 3.9 & 3.5 (1.7 to 7.3$)$ \\
\hline Personality disorders & 85 & 8.2 & $2.6(2.0$ to 3.5$)$ & 37 & 3.6 & 2.7 (1.9 to 3.8$)$ & 13 & 6.3 & $2.8(1.4$ to 5.6$)$ & 8 & 3.9 & $1.9(1.0$ to 3.9$)$ \\
\hline Other mental disorders & 233 & 22.5 & 1.8 (1.5 to 2.2$)$ & 115 & 11.1 & $1.2(1.0$ to 1.5$)$ & 30 & 14.5 & $1.6(0.9$ to 2.7$)$ & 27 & 13.0 & 0.9 (0.6 to 1.4$)$ \\
\hline Musculoskeletal disorders & 23 & 2.2 & $0.9(0.6$ to 1.4$)$ & 43 & 4.2 & 0.8 (0.6 to 1.2$)$ & $<7$ & 1.9 & $1.1(0.4$ to 3.1$)$ & 7 & 3.4 & $0.5(0.2$ to 1.0$)$ \\
\hline Other somatic disorders & 36 & 3.5 & $1.1(0.8$ to 1.6$)$ & 55 & 5.3 & $0.9(0.7$ to 1.2$)$ & $<7$ & 1.0 & $0.4(0.1$ to 1.8$)$ & 22 & 10.6 & $1.2(0.7$ to 1.9$)$ \\
\hline \multicolumn{13}{|l|}{ Number of years on DP in 2005} \\
\hline 1 & 95 & 17.1 & 1 & 47 & 9.8 & 1 & 7 & 9.2 & 1 & 20 & 15.3 & 1 \\
\hline $2-3$ & 254 & 45.6 & $0.9(0.7$ to 1.1$)$ & 191 & 39.9 & $1.1(0.8$ to 1.5$)$ & 39 & 51.3 & 1.9 (0.9 to 4.2$)$ & 58 & 44.3 & $0.8(0.5$ to 1.3$)$ \\
\hline$\geq 4$ & 208 & 37.3 & $1.0(0.8$ to 1.3$)$ & 241 & 50.3 & 1.3 (1.0 to 1.8$)$ & 30 & 39.5 & 2.0 (0.9 to 4.5$)$ & 53 & 40.5 & 0.7 (0.4 to 1.1$)$ \\
\hline \multicolumn{13}{|l|}{ DP grade in 2005} \\
\hline Part-time & 56 & 5.4 & 1 & 70 & 6.8 & 1 & 7 & 3.4 & 1 & 19 & 9.2 & 1 \\
\hline Full-time & 501 & 48.6 & $2.2(1.6$ to 2.9$)$ & 409 & 39.6 & $2.2(1.7$ to 2.8$)$ & 69 & 33.3 & $2.4(1.1$ to 5.1$)$ & 112 & 54.1 & 2.2 (1.3 to 3.6$)$ \\
\hline
\end{tabular}


Table 4 Multivariate HRs with 95\% Cl for suicide attempt and suicide (2006-2010), in 46515 individuals, aged 19-64 years and living in Sweden on 31 December 2004, and on disability pension (DP) due to common mental disorders in 2005 , stratified by gender*

\begin{tabular}{|c|c|c|c|c|}
\hline \multirow[b]{2}{*}{ Characteristic } & \multicolumn{2}{|l|}{ Suicide attempt } & \multicolumn{2}{|l|}{ Suicide } \\
\hline & $\begin{array}{l}\text { Women } \\
\text { HR (95\% Cl) }\end{array}$ & $\begin{array}{l}\text { Men } \\
\text { HR (95\% Cl) }\end{array}$ & $\begin{array}{l}\text { Women } \\
\text { HR }(95 \% \mathrm{CI})\end{array}$ & $\begin{array}{l}\text { Men } \\
\text { HR (95\% Cl) }\end{array}$ \\
\hline \multicolumn{5}{|l|}{ Main DP diagnosis } \\
\hline Depressive disorders & 1 & 1 & 1 & 1 \\
\hline Anxiety disorders & 1.0 (0.9 to 1.2$)$ & 1.0 (0.8 to 1.2$)$ & 0.9 (0.6 to 1.4$)$ & $1.3(0.8$ to 2.0$)$ \\
\hline Stress-related mental disorders & 0.8 (0.6 to 1.0$)$ & $0.6(0.4$ to 0.9$)$ & 0.9 (0.5 to 1.6$)$ & $0.4(0.2$ to 0.9$)$ \\
\hline \multicolumn{5}{|l|}{ Secondary DP diagnosis } \\
\hline No secondary diagnosis & 1 & 1 & 1 & 1 \\
\hline Substance abuse disorders & 2.1 (1.5 to 2.9$) \dagger$ & $1.6(1.0$ to 2.4$)$ & $3.3(1.5$ to 7.1$) \dagger$ & $0.8(0.3$ to 1.7$)$ \\
\hline Personality disorders & $1.4(1.1$ to 1.8$) \dagger$ & $1.4(1.0$ to 2.1$)$ & $1.8(0.9$ to 3.5$)$ & 0.9 (0.4 to 1.8$)$ \\
\hline Other mental disorders & $1.3(1.1$ to 1.5$) \dagger$ & $1.2(0.9$ to 1.6$)$ & 1.1 (0.6 to 1.8$)$ & 0.9 (0.6 to 1.5$)$ \\
\hline Musculoskeletal disorders & $1.1(0.8$ to 1.5$)$ & $0.7(0.4$ to 1.4$)$ & $0.8(0.3$ to 2.0$)$ & 0.7 (0.3 to 1.9$)$ \\
\hline Other somatic disorders & $1.1(0.9$ to 1.5$)$ & $1.0(0.7$ to 1.6$)$ & $1.6(0.9$ to 3.0$)$ & $0.8(0.4$ to 1.7$)$ \\
\hline \multicolumn{5}{|l|}{ Number of years on DP in 2005} \\
\hline 1 & 1 & 1 & 1 & 1 \\
\hline $2-3$ & $0.9(0.7$ to 1.1$)$ & $1.0(0.7$ to 1.4$)$ & $1.0(0.5$ to 1.8$)$ & $1.0(0.6$ to 1.8$)$ \\
\hline$\geq 4$ & 1.0 (0.8 to 1.2$)$ & 0.9 (0.6 to 1.3$)$ & $1.0(0.5$ to 1.8$)$ & 0.7 (0.4 to 1.3$)$ \\
\hline \multicolumn{5}{|l|}{ DP grade in 2005} \\
\hline Part-time & 1 & 1 & 1 & 1 \\
\hline Full-time & $1.7(1.4$ to 2.2$) \dagger$ & 0.9 (0.6 to 1.3$)$ & 1.5 (0.8 to 2.6$)$ & 1.7 (0.9 to 3.3$)$ \\
\hline
\end{tabular}

1.2-1.4) in the crude models, compared with individuals with a DP duration of 1 year. These associations were not statistically significant in the adjusted models. In the univariate analyses, full-time DP was associated with a higher risk of suicidal behaviour in both genders and age categories (range of HRs 1.3-3.1) compared with

Table 5 Multivariate HRs with 95\% Cl for suicide attempt and suicide (2006-2010), in 46515 individuals, aged 19-64 years and living in Sweden on 31 December 2004, and on disability pension (DP) due to common mental disorders in 2005 ,

stratified by age*

\begin{tabular}{|c|c|c|c|c|}
\hline \multirow[b]{2}{*}{ Characteristic } & \multicolumn{2}{|l|}{ Suicide attempt } & \multicolumn{2}{|l|}{ Suicide } \\
\hline & $\begin{array}{l}\text { Age } 19-44 \text { years } \\
\text { HR }(95 \% \mathrm{Cl})\end{array}$ & $\begin{array}{l}\text { Age } 45-64 \text { years } \\
\text { HR }(95 \% \mathrm{Cl})\end{array}$ & $\begin{array}{l}\text { Age } 19-44 \text { years } \\
\text { HR }(95 \% \mathrm{Cl})\end{array}$ & $\begin{array}{l}\text { Age } 45-64 \text { years } \\
\text { HR }(95 \% \mathrm{Cl})\end{array}$ \\
\hline \multicolumn{5}{|l|}{ Main DP diagnosis } \\
\hline Depressive disorders & 1 & 1 & 1 & 1 \\
\hline Anxiety disorders & $1.1(0.9$ to 1.3$)$ & 0.9 (0.8 to 1.2$)$ & 1.7 (1.0 to 3.0$)$ & 0.9 (0.6 to 1.3$)$ \\
\hline Stress-related mental disorders & $0.8(0.6$ to 1.1$)$ & 0.7 (0.5 to 0.9$)$ & $1.7(0.8$ to 3.6$)$ & $0.4(0.2$ to 0.8$) \dagger$ \\
\hline \multicolumn{5}{|l|}{ Secondary DP diagnosis } \\
\hline No secondary diagnosis & 1 & 1 & 1 & 1 \\
\hline Substance abuse disorders & 2.3 (1.6 to 3.3$) \dagger$ & $1.5(1.1$ to 2.2$) \dagger$ & 2.6 (1.1 to 6.1$)$ & 1.0 (0.5 to 2.3$)$ \\
\hline Personality disorders & $1.5(1.1$ to 2.0$) \dagger$ & $1.6(1.1$ to 2.2$) \dagger$ & $1.7(0.8$ to 3.4$)$ & 1.1 (0.5 to 2.3$)$ \\
\hline Other mental disorders & 1.5 (1.2 to 1.9$) \dagger$ & 1.0 (0.8 to 1.3$)$ & $1.3(0.8$ to 2.4$)$ & 0.8 (0.5 to 1.3$)$ \\
\hline Musculoskeletal disorders & $1.1(0.7$ to 1.8$)$ & 0.9 (0.7 to 1.3$)$ & 1.7 (0.6 to 4.9$)$ & 0.6 (0.3 to 1.3$)$ \\
\hline Other somatic disorders & $1.2(0.8$ to 1.8$)$ & $1.1(0.8$ to 1.4$)$ & $0.5(0.1$ to 2.1$)$ & $1.3(0.8$ to 2.2$)$ \\
\hline \multicolumn{5}{|l|}{ Number of years on DP in 2005} \\
\hline 1 & 1 & 1 & 1 & 1 \\
\hline $2-3$ & $0.8(0.7$ to 1.1$)$ & 1.0 (0.7 to 1.3$)$ & 1.8 (0.8 to 4.0$)$ & 0.7 (0.4 to 1.2$)$ \\
\hline$\geq 4$ & $0.9(0.7$ to 1.4$)$ & $1.0(0.7$ to 1.4$)$ & 1.7 (0.7 to 3.8$)$ & 0.6 (0.3 to 0.9$)$ \\
\hline \multicolumn{5}{|l|}{ DP grade in 2005} \\
\hline Part-time & 1 & 1 & 1 & 1 \\
\hline Full-time & $1.4(1.1$ to 1.9$) \dagger$ & 1.5 (1.1 to 1.9$) \dagger$ & $1.3(0.6$ to 3.0$)$ & 1.7 (1.0 to 2.8$)$ \\
\hline
\end{tabular}


individuals on part-time DP. After multivariate adjustment, these associations remained significant (range of HRs 1.4-1.7) except for suicide attempt and suicide among men, and suicide in women and younger individuals. Statistically significant interaction was observed between gender and DP grade $(p=0.001)$ in relation to subsequent suicide attempt. Women on full-time DP had a higher risk of future suicide attempt than women who were on part-time DP. No such association was found for their male counterparts (table 4).

\section{DISCUSSION}

In this nationwide prospective cohort study of people on DP due to CMD, we explored the risk of suicidal behaviour related to DP diagnoses, duration and grade. Stress-related mental disorders as the main DP diagnosis was associated with a lower risk of subsequent suicidal behaviour compared with depressive disorders as the main DP diagnosis. Moreover, comorbid substance abuse disorders and personality disorders as well as full-time DP were associated with a higher risk of suicide attempt and suicide during follow-up. Some gender and age differences in these associations emerged.

To the best of our knowledge, this is the first study to investigate different measures of DP as risk factors for suicidal behaviour in individuals on DP due to CMD. The main strengths of our study are the use of highquality population-based Swedish nationwide register data $^{34}{ }^{35}$ and the prospective cohort design with several years of follow-up. We included register data from different sources on the whole working-age population of Sweden and thereby avoided selection and recall bias. Moreover, there was no loss to follow-up and all data were register based, including physician-based diagnoses -that is, not based on self-reports. The study group was large and the statistical power was sufficient even with regard to such uncommon outcomes as suicide attempt and suicide. This study also had the opportunity to include a wide range of potential confounders such as educational level, family situation, country of birth, type of area of residence, and previous healthcare.

There are some limitations of the study. In spite of the long follow-up, there were only 207 suicides, leading to wide CIs. Another limitation is that only the main, and when given, the secondary DP diagnoses could be included. Additional diagnoses that might have been stated in the sickness certificate as contributing to patients' work incapacity were not included in the MiDAS register. Having such information might have improved the analyses; however, most studies on DP only have access to the main diagnosis. A topic of frequent discussion in this research field is the validity of DP diagnoses. There are no studies on this, so far. A study conducted in Sweden in 1991 showed high validity of sick-leave diagnoses compared with diagnoses from medical records. ${ }^{36}$ In addition, DP in most cases is preceded by long-term absence due to sickness and is granted after a long process of medical evaluation and work capacity assessment, as DP benefits are often paid for several years. ${ }^{3}$ Moreover, owing to the stigma surrounding mental diagnoses, ${ }^{37} 38$ the validity of mental DP diagnoses can be assumed to be good, meaning that people with a mental DP diagnosis are likely to have a mental disorder. On the other hand, this also means that some individuals with mental disorders might not have been given a mental diagnosis as the main DP diagnosis, but as a secondary diagnosis to a somatic main DP diagnosis. Thus, they would not be included in this study. This can also be seen as a strength, as our group of CMDs is more strictly defined than if secondary diagnoses were also used for inclusion, or as a limitation, as we do not know if including them would have affected the results. Further studies on these issues are required.

Moreover, the stigma of mental disorders might have led to under-reporting of some mental disorders as secondary diagnoses. The reported secondary diagnoses might therefore reflect greater medical severity. It should also be mentioned that we considered suicide attempts that led to inpatient care, thus the results are mainly valid for suicide attempts of greater medical severity. In addition, it is important to keep in mind that DP not only reflects to what extent the disease affects an individual's work capacity, but also factors at other structural levels such as possibilities and demands at the labour market, adjustment policies, attitudes, and the economic situation of a country. ${ }^{39}$ Such factors may influence not only the level of DP in a country $^{39} 40$ but also the level of suicidal behaviour, ${ }^{41} 42$ which thus may have affected the results of this study.

In this study, the risk of subsequent suicidal behaviour related to a main DP diagnosis of anxiety did not differ from that of a main DP diagnosis of depressive disorder, while those with stress-related mental disorders as the main DP diagnosis had a lower risk of future suicidal behaviour. This is in line with a study on diagnosisspecific sickness absence that suggested higher risk estimates for subsequent suicide among people on sickness absence due to depressive and anxiety disorders than due to stress-related mental disorders, after adjustment for sociodemographic factors. ${ }^{43}$

There was a significant interaction between age and main DP diagnoses in relation to suicide. While there was a significantly lower risk of suicide in the older age group (45-64 years) with a main DP diagnosis of 'stressrelated mental disorders' compared with 'depressive disorders', this association was not found in the younger individuals. On the other hand, 'anxiety disorders' as the main diagnosis were associated with a higher risk of subsequent suicide in the individuals aged 19-44 years, compared with the same age group with a main DP diagnosis of 'depressive disorders' in the multivariate analyses. One likely explanation of such findings is age differences in the association of mental disorders with suicide risk. ${ }^{14} 44$ Anxiety disorders often have an early onset, and younger individuals may tend to have greater impulsivity, which might contribute to suicidal behaviour. ${ }^{45}$ Moreover, early-onset anxiety disorders leading to 
DP might be more difficult to treat and probably are associated with a high degree of comorbidity. Anxiety disorders are highly comorbid with depressive or personality disorders, ${ }^{14} 1546$ and also might have contributed to suicidal behaviour among these young individuals. Early detection and adequate treatment of anxiety disorders for prevention of suicidal behaviour might be of particular importance, ${ }^{15}{ }^{16}$ especially in younger individuals. These associations warrant further investigation.

Our analyses show that having a mental secondary DP diagnosis was associated with a higher risk of suicide attempt and suicide compared with not having a secondary diagnosis. This is in line with previous research on the general population ${ }^{14}{ }^{47}$ or individuals with a diagnosed mental disorder. ${ }^{17} 18{ }^{48}$ Moreover, we found that substance abuse disorder was the strongest predictor of subsequent suicide attempt. These findings are consistent with previous studies showing that substance abuse is a strong risk factor for suicidal behaviour. ${ }^{19} 4749$

A significant interaction was observed between gender and substance abuse as secondary DP diagnosis in relation to subsequent suicide. Substance abuse might be less prevalent and less frequently diagnosed in women than men. Therefore, it can be hypothesised that having such a DP diagnosis might be a reflection of a severe medical condition, particularly in women, which in turn might be a reason for their higher suicide risk. ${ }^{14} 1949$ It is therefore possible that health consequences of substance abuse disorders might be worse in women than men. ${ }^{50}$ Moreover, substance abuse disorders may aggravate an existing comorbid depression, which itself is a risk factor for suicidal behaviour. ${ }^{50-53}$

Personality disorder as a secondary DP diagnosis was strongly associated with a higher risk of suicide attempt compared with those who did not have any secondary DP diagnosis. Current literature suggests that personality disorder, comorbid with depression or by itself, involves a higher risk of suicide attempt. ${ }^{545}$

Full-time DP was associated with a higher risk of suicidal behaviour compared with part-time DP. This is in line with a previous study reporting a higher risk of suicidal behaviour associated with full-time compared with part-time sickness absence. ${ }^{56}$ Full-time DP might here be associated with a greater severity of the underlying disorder. On the other hand, full-time DP might be related to an alteration in health behaviour (regarding alcohol consumption, smoking, physical activity, diet, etc) or to social isolation, ${ }^{8}{ }^{57}$ which might be associated with total exclusion from the labour market. ${ }^{9}$ More knowledge is required on such associations. ${ }^{8}$

Statistically significant interaction was observed between gender and DP grade: women with full-time DP had a higher risk of subsequent suicide attempt than women with part-time DP. The proportion of women on part-time DP tends to be much higher compared with men in Sweden. ${ }^{3}$ It might be anticipated that, if women are granted full-time DP, they might have a greater severity of the underlying mental disorder and therefore be at higher risk of subsequent suicide attempt. ${ }^{56}$ Further studies are warranted to investigate pathways to suicidal behaviour related to DP grade.

\section{CONCLUSION}

This first study of associations between measures of DP due to CMD with subsequent risk of suicidal behaviour among individuals on such DP found several such associations. In general, depressive disorders as the main DP diagnosis and substance abuse or personality disorder as the secondary DP diagnosis were risk markers for subsequent suicidal behaviour in such individuals. Some gender and age differences in these associations emerged. Approaches for intervention in this group of 'disability pensioners' should therefore consider the individual variation in risk factors with regard to gender and age. Particular attention should be paid to younger individuals on DP due to anxiety disorders because of the higher suicide risk.

Contributors EM-R was responsible for the core idea, and all authors contributed to the study design. SGR and EM-R carried out the data analyses and drafted the manuscripts. SGR, KA, JJ and EM-R participated in interpretation of results, critically revised the manuscript for important intellectual content, contributed to successive drafts, and agreed on the final version. All authors read and approved the final manuscript.

Funding The Swedish Research Council for Health, Working Life and Welfare, the Swedish Research Council (Project numbers: K2009-61P-21304-04-4; K2009-61X-21305-01-1; K2011-80P-21782-01-4) and the Karolinska Institutet's funding for doctoral students.

Competing interests None declared.

Ethics approval The Regional Ethics Review Board of Stockholm, Sweden (Dnr 2007/762-31)

Provenance and peer review Not commissioned; externally peer reviewed.

Data sharing statement No additional data are available.

Open Access This is an Open Access article distributed in accordance with the Creative Commons Attribution Non Commercial (CC BY-NC 4.0) license, which permits others to distribute, remix, adapt, build upon this work noncommercially, and license their derivative works on different terms, provided the original work is properly cited and the use is non-commercial. See: http:// creativecommons.org/licenses/by-nc/4.0/

\section{REFERENCES}

1. Sickness, disability and work: breaking the barriers. A synthesis of findings across OECD countries. Paris: OECD, 2010. ISBN: 978-92-64-08884-9; ISBN: 978-92-64-08885-6.

2. Alexanderson K, Norlund A. Swedish Council on Technology Assessment in Health Care (SBU). Chapter 1. Aim, background, key concepts, regulations, and current statistics. Scand J Public Health Supp/ 2004;63:12-30.

3. Social Insurance Agency (försäkringskassan). Social Insurance in Figures 2013. Sweden: The Social Insurance Agency, 2014. ISBN: 978-91-7500-376-4; ISSN: 2000-1703.

4. Henderson M, Harvey SB, Overland S, et al. Work and common psychiatric disorders. J R Soc Med 2011;104:198-207.

5. Mykletun A, Overland S, Dahl AA, et al. A population-based cohort study of the effect of common mental disorders on disability pension awards. Am J Psychiatry 2006;163:1412-18.

6. Järvisalo J, Anderson B, Boedeker W, et al. eds. Mental disorders as a major challenge in prevention of work disability: experiences in Finland, Germany, the Netherlands and Sweden. Helsinki: Kela, 2005.

7. Kupfer DJ, Frank E, Phillips ML. Major depressive disorder: new clinical, neurobiological, and treatment perspectives. Lancet 2012;379:1045-55. 
8. Vingård E, Alexanderson $\mathrm{K}$, Norlund $\mathrm{A}$. Swedish Council on Technology Assessment in Health Care (SBU). Chapter 9. Consequences of being on sick leave. Scand J Public Health Supp/ 2004;63:207-15.

9. Waddell G, Burton K. Is working good for your health and well-being? UK: Published by TSO (The Stationery Office), 2006

10. Bryngelson A, Asberg M, Nygren A, et al. All-cause and causespecific mortality after long-term sickness absence for psychiatric disorders: a prospective cohort study. PLOS ONE 2013;8:e67887.

11. Karlsson NE, Carstensen JM, Gjesdal S, et al. Mortality in relation to disability pension: findings from a 12-year prospective population-based cohort study in Sweden. Scand J Public Health 2007;35:341-7.

12. Johansson $\mathrm{AE}$, Johansson $\mathrm{U}$. Disability pension and everyday life: a period of transition and subjective aspects of future occupational life. Work 2011;40:375-84

13. Rahman S, Alexanderson K, Jokinen J, et al. Risk factors for suicidal behaviour in individuals on disability pension due to common mental disorders-a nationwide register-based prospective cohort study in Sweden. PLOS ONE 2014;9:e98497.

14. Hawton K, van Heeringen K. Suicide. Lancet 2009;373:1372-81.

15. Fawcett $\mathrm{J}$. The detection and consequences of anxiety in clinical depression. J Clin Psychiatry 1997;58(Supp 8):35-40.

16. Fawcett $\mathrm{J}$. Targeting treatment in patients with mixed symptoms of anxiety and depression. J Clin Psychiatry 1990;51:40-3.

17. Hawton $\mathrm{K}$, Casañas I Comabella C, Haw $C$, et al. Risk factors for suicide in individuals with depression: a systematic review. J Affect Disord 2013;147:17-28.

18. Kanwar A, Malik S, Prokop LJ, et al. The association between anxiety disorders and suicidal behaviours: a systematic review and meta-analysis. Depress Anxiety 2013;30:917-29.

19. Cavanagh JTO, Carson AJ, Sharpe M, et al. Psychological autopsy studies of suicide: a systematic review. Psychol Med 2003;33:395-405.

20. Crump C, Sundquist K, Sundquist J, et al. Sociodemographic, psychiatric and somatic risk factors for suicide: a Swedish national cohort study. Psychol Med 2014;44:279-89.

21. Laaksonen M, Gould R. The effect of municipality characteristics on disability retirement. Eur J Public Health 2014;24:116-21.

22. Leinonen T, Martikainen P, Lahelma E. Interrelationships between education, occupational social class, and income as determinants of disability retirement. Scand J Public Health 2012;40:157-66.

23. Osterberg T, Gustafsson B. Disability pension among immigrants in Sweden. Soc Sci Med 2006;63:805-16.

24. Pompili M, Innamorati M, Szanto K, et al. Life events as precipitants of suicide attempts among first-time suicide attempters, repeaters, and non-attempters. Psychiatry Res 2011:186:300-5.

25. Leinonen T, Martikainen P, Laaksonen M, et al. Excess mortality after disability retirement due to mental disorders: variations by socio-demographic factors and causes of death. Soc Psychiatry Psychiatr Epidemiol 2014;49:639-49.

26. Björkenstam C, Alexanderson K, Björkenstam E, et al. Diagnosis-specific disability pension and risk of all-cause and cause-specific mortality-a cohort study of 4.9 million inhabitants in Sweden. BMC Public Health 2014:14:1247.

27. Jonsson U, Alexanderson K, Kjeldgård L, et al. Diagnosis-specific disability pension predicts suicidal behaviour and mortality in young adults: a nationwide prospective cohort study. BMJ Open 2013;3. pii: e002286.

28. WHO. International Statistical Classification of Diseases and Related Health Problems, 10 revision (ICD 10). World Health Organization; 2010.

29. Koopmans PC, Bültmann U, Roelen CA, et al. Recurrence of sickness absence due to common mental disorders. Int Arch Occup Environ Health 2011;84:193-201.

30. Deverill C, King M. Common Mental Disorders. In: McManus S, Meltzer H, Brugha T, Bebbington P, Jenkins R, eds. Adult psychiatric morbidity in England. London: The NHS Information Centre for health and social care, 2009:25-7.

31. Rutz EM, Wasserman D. Trends in adolescent suicide mortality in the WHO European Region. Eur Child Adolesc Psychiatry 2004; 13:321-31.

32. Allebeck P, Allgulander $\mathrm{C}$, Henningsohn $\mathrm{L}$, et al. Causes of death in a cohort of 50465 young men-validity of recorded suicide as underlying cause of death. Scand J Soc Med 1991;19:242-7.

33. Mittendorfer-Rutz E, Rasmussen F, Wasserman D. Restricted fetal growth and adverse maternal psychosocial and socioeconomic conditions as risk factors for suicidal behaviour of offspring: a cohort study. Lancet 2004;364:1135-40.

34. Ludvigsson JF, Andersson E, Ekbom A, et al. External review and validation of the Swedish national inpatient register. BMC Public Health 2011;11:450.

35. Socialstyrelsen. The cause of death register. Stockholm, Sweden: National Board of Health and Welfare, 2013. August 2013. Report No.: ISSN 1400-3511; ISBN 978-91-7555-090-9; Report no. 2013-8-6.

36. Ljungdahl LO, Bjurulf $P$. The accordance of diagnoses in a computerized sick-leave register with doctor's certificates and medical records. Scand J Soc Med 1991;19:148-53.

37. Shrivastava A, Johnston M, Bureau Y. Stigma of mental illness-1: clinical reflections. Mens Sana Monogr 2012;10:70-84.

38. Lauber C. Stigma and discrimination against people with mental illness: a critical appraisal. Epidemiol Psichiatr Soc 2008;17: 10-13.

39. Allebeck P, Mastekaasa A. Swedish Council on Technology Assessment in Health Care (SBU). Chapter 3. Causes of sickness absence: research approaches and explanatory models. Scand $J$ Public Health Suppl 2004;63:36-43.

40. Gustafsson K, Aronsson G, Marklund S, et al. Peripheral labour market position and risk of disability pension: a prospective population-based study. BMJ Open 2014;4:e005230.

41. Turecki G, Brent DA. Suicide and suicidal behaviour. Lancet 2015;387:29.

42. Haw C, Hawton K, Gunnell D, et al. Economic recession and suicidal behaviour: Possible mechanisms and ameliorating factors. Int J Soc Psychiatry 2015;61:73-81.

43. Mittendorfer-Rutz E, Kjeldgård L, Runeson B, et al. Sickness absence due to specific mental diagnoses and all-cause and cause-specific mortality: a cohort study of 4.9 million inhabitants of Sweden. PLOS ONE 2012;7:e45788

44. Conwell $Y$, Duberstein PR, Cox $\mathrm{C}$, et al. Relationships of age and axis I diagnoses in victims of completed suicide: a psychological autopsy study. Am J Psychiatry 1996;153:1001-8.

45. McGirr A, Renaud J, Bureau A, et al. Impulsive-aggressive behaviours and completed suicide across the life cycle: a predisposition for younger age of suicide. Psychol Med 2008;38:407-17.

46. Jylhä $\mathrm{P}$, Rosenström $\mathrm{T}$, Mantere $\mathrm{O}$, et al. Personality disorders and suicide attempts in unipolar and bipolar mood disorders. J Affect Disord 2016;190:632-9.

47. Kessler RC, Borges G, Walters EE. Prevalence of and risk factors for lifetime suicide attempts in The National Comorbidity Survey. Arch Gen Psychiatry 1999;56:617-26.

48. Isometsä E. Suicidal behaviour in mood disorders-who, when, and why? Can J Psychiatry 2014;59:120-30.

49. Vijayakumar L, Kumar MS, Vijayakumar V. Substance use and suicide. Curr Opin Psychiatry 2011;24:197-202.

50. Erol A, Karpyak VM. Sex and gender-related differences in alcohol use and its consequences: Contemporary knowledge and future research considerations. Drug Alcohol Depend 2015;156:1-13.

51. Boykoff N, Schneekloth TD, Hall-Flavin D, et al. Gender differences in the relationship between depressive symptoms and cravings in alcoholism. Am J Addict 2010;19:352-6.

52. Goldstein RB, Dawson DA, Chou SP, et al. Sex differences in prevalence and comorbidity of alcohol and drug use disorders: results from wave 2 of The National Epidemiologic Survey on Alcohol and Related Conditions. J Stud Alcohol Drugs 2012;73: 938-50.

53. Moscato BS, Russell M, Zielezny M, et al. Gender differences in the relation between depressive symptoms and alcohol problems: a longitudinal perspective. Am J Epidemiol 1997:146:966-74

54. Amore M, Innamorati M, Vittorio CD, et al. Suicide attempts in major depressed patients with personality disorder. Suicide Life Threat Behav 2014;44:155-66.

55. Paris J. Chronic suicidality among patients with borderline personality disorder. Psychiatr Serv 2002;53:738-42.

56. Ishtiak-Ahmed K, Perski A, Mittendorfer-Rutz E. Predictors of suicidal behaviour in 36,304 individuals sickness absent due to stress-related mental disorders-a Swedish register linkage cohort study. BMC Public Health 2013;13:492.

57. Floderus B, Göransson S, Alexanderson K, et al. Self-estimated life situation in patients on long-term sick leave. $J$ Rehabil Med 2005;37:291-9. 